\title{
PERSONALIDAD Y PREDICCION
}

\section{M. ${ }^{a}$ Dolores Avia}

Universidad Complutense de Madrid

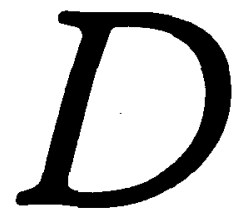

Desde hace tiempo, las teorías de la personalidad pueden dividirse, filosóficamente hablando, entre las que siguen a Leibnitz y las partidarias de Locke. Para explicar la conducta, afirman las primeras que hay que mirar hacia dentro; las segunda, que es mejor mirar hacia afuera. Aunque no tendría por qué haber sido así, las primeras se han centrado en los facto:es estables y permanentes del comportamiento humano y las segundas en los aspectos variables. Digo que no tendría por qué haber sido así porque todos sabemos también que las personas cambian - unas más que otras - y las situaciones -especialmente algunas - permanecen. Con esto entro de lleno en el tema que compone este dossier. Permanencia o cambio, identificados respectivamente con individuo y situación, ha sido el conflicto típico que ha atormentado durante largo tiempo a los psicólogos de la personalidad, por cierto bastante innecesariamente, como los artículos que siguen podrán al lector de manifiesto.

En los movimientos científicos suelen darse oscilaciones pendulares y en este caso la gran aceptación que tuvieron inicialmente los enfoques basados en la permanencia se vieron sustituidos no hace mucho por orientaciones inclinadas al cambio. Como puede encontrarse en muchos manuales al respecto, y como yo misma he comentado en otra parte (1), lo que ocurre ahora es que casi nadie «bien visto" se atreve a hablar de la consistencia de la personalidad.

Es este estado de cosas el que, con gran intuición y admirables dosis de humor, se ve desafiado en el artículo de Bem y Allen:

«...(Hay una)... gran discrepancia entre la intuición, que nos dice que los individuos muestran, de hecho, cierta consistencia transituacional en su conducta, y la amplia literatura empírica que nos dice lo contrario. ¿De qué fiarnos, de la intuición o de la investigación? Una de las dos debe ser errónea... (pág. 4) .... No negamos las bien documentadas tendencias e ilusiones que llenan nuestra intuición... Pero en términos de la lógica subyacente y de la adecuación a la realidad, creemos que nuestras intuiciones son correctas, y la investigación errónea» (pág. 9). 
Yo también, con Bem y Allen, considero que hay más consistencia de la que los teóricos situacionales han señalado $y$, como dice Block (2), es probable que el sombrío panorama que se desprende al avaluar la literatura sobre personalidad dependa, en gran parte, de que no hemos enfocado bien al problema - como dicen los ingleses, we have missed the pointdebido, quizá, a un empirismo mal entendido.

Pervin (3) ha señalado acertadamente que lo que nuestra intuición realmente nos dice no es que nosotros somos siempre consistentes, sino que captamos perfectamente los dos aspectos duales e inseparables de nuestro comportamiento: una cierta consistencia, sin la cual perderíamos el sentido de identidad y un cambio relativo, que de no ocurrir nos impediría toda posibilidad de adaptación.

Cuando tropecé por primera vez con el artículo de Bem y Allen encontré en él una serie de valores, para mí de gran y raro interés. El primero, su afirmación, compartida por muchos autores, de que el conflicto consistencia-variabilidad es una falsa dicotomía. El segundo, y éso ya no lo han dicho otros autores, es su observación de que la verdadera dicotomía no está entre individuo y situación, sino entre enfoques nomotéticos y enfoques idiográficos; es, en suma, un conflicto metodológico. Bem y Allen denuncian la falacia nomotética que ya señaló Allport, indicando que la mayoría de las investigaciones en personalidad, de uno y otro signo, se basan en supuestos nomotéticos, lo que conduce necesariamente a un "veredicto" de inconsistencia. Porque, dicen y demuestran Bem y Allen, las personas no somos, en general, variables e inconsistentes; somos consistentes de modo diferente unas de otras, en aspectos distintos, $\mathrm{y}$, desde luego, unos en mayor medida que otros. A su vez, la variabilidad de nuestra conducta la producen, para algunos, ciertas situaciones, que no son las mismas de las que originan cambios en otros.

A veces, explicando estos temas, he tratado confusamente de decir lo que tan acertadamente expresan Bem y Allen en su artículo. Los grandes aciertos que, a mi entender, encierra la teoría cognitiva de Kelly con su formulación de la personalidad como un sistema de constructos, encajan perfectamente con el punto central que señalan estos autores: como investigadores decidimos, a la vista de las bajas correlaciones entre datos de personalidad, que nuestros sujetos son inconsistentes, sin pararnos a pensar que los estamos imponiendo nuestro sistema lógico, el orden de nuestro sistema de constructos, que en el mejor de los casos coincidirá con el de algunos individuos, pero raras veces con el de todos.

Uno de los aspectos positivos de este trabajo, sorprendente dada la situación en el campo de la personalidad, es que ofrece soluciones y abre nuevas vías de investigación. Formulada en términos poco técnicos, la solución consistiría en preguntar a los individuos si les parece relevante para su personalidad el rasgo que estudia el investigador; excluir aquellos que respondan negativamente y trabajar con el resto. A los que se excluyen habría de estudiarlos según otras características y si sistemáticamente resultan ser altamente variables en los aspectos seleccionados... esas serían las personas que podrían predecirse fundamentalmente atendiendo a la situación.

El trabajo de Bem y Funder revela la sagacidad de los autores en hacer algo más que una palabra de las recientemente defendidas «tendencias interactivas» en personalidad. Cabría reparar de nuevo en que cuando pensamos en términos personales, y nò científicos, reconocemos la interacción entre individuo y situación mucho más de lo que lo hacemos al dirigir investigaciones. Nuestros interrogantes diarios responden casi siempre, si se me 
permite la alusión cinematográfica, al "qué puede hacer una chica como yo en un sitio como éste». Raramente nos preocupamos por nosotros sin que exista, aunque sea implícita, una referencia a una situación. Menos veces aún nos preocupamos sólo por una situación, sin pensar en las ventajas o inconvenientes que conlleva para nosotros o para otras personas.

La vía que abren Bem y Funder ante el proceder de los científicos, empecinadamente centrados bien en el individuo, bien en la situación, es la de emprender esa difícil y poco común tarea de clasificar una situación, pero de una manera ciertamente interactiva: definiendo la «personalidad» de las situaciones. para ello las categorizan indicando las conductas que cada situación tiende a elicitar en diferentes individuos-tipo. Es algo así como el negativo de lo que han hecho las teorias de la conducta: definir a los individuos por sus respuestas a las situaciones. La viabilidad de este enfoque se pone a prueba en tres situaciones experimentales diferentes.

Para no repetir lo que vendrá a continuación, voy a referirme únicamente a la primera de ellas.

Por mi vinculación a los trabajos de demora de la gratificación (4), no puedo sino coincidir con los análisis que Bem y Funder hacen de su primer experimento. $\mathrm{Si}$ los niños que toleran largo tiempo una situación frustrante son, en términos de personalidad, responsables, considerados, y autoexigentes, pero también sumisos, pasivos y obedientes, ino nos habla todo esto de las condiciones de la situación en que se encuentran? Los efectos de la demanda y de la expresión causada por el experimentador dan cuenta, quizá, de muchas conductas que hemos atribuido alegremente a la variable que estábamos estudiando.

Común a los dos trabajos es su ecuanimidad al evaluar en su justo término los resultados de las investigaciones. Así, señalan que, de la superioridad de una teoría para predecir ciertas conductas -el cambio de actitudes en el experimento 3 de Bem y Funder - no se desprende necesariamente que dicha superioridad se mantenga en otras áreas. Tantos experimentos «cruciales» para comparar teorías alternativas, parecen sugerir los autores, son necesariamente limitados. No podría ser de otra manera.

Al final de su trabajo Bem y Funder aluden, humorísticamente, a un hipotético artículo sobre el que ahora trabajan, y que servirá de continuación a éstos. En él intentas predecir a todas las personas en todas las situaciones. Con ello, invitan a reflexionar sobre un punto en el que la literatura no ha insistido suficientemente. ¿No estaremos, a fin de cuentas, exagerando la necesidad de predecir, exacta y precisamente, la conducta humana? ¿No será éste un objetivo imposible de lograr? «Los problemas que nos encontramos frecuentemente al predecir la conducta en situaciones complejas no significan, quizá, que todos nuestros principios sobre el funcionamiento de las personas carezcan de fundamento", dice Pervin (5). Significan, probablemente, que pedimos a nuestra disciplina más de lo que es capaz de dar. Al fin y al cabo, y aunque a veces no lo parezca, la psicología de la personalidad debe servir para estudiar a las personas. $Y$ las personas, aunque ciertamente no seamos muy libres, tampoco somos, por fortuna, completamente predictibles. 


\section{Referencias}

(1) AVIA, M. D. Personalidad: ¿consistencia intrapsiquica o especificidad situacional? Una alternativa interactiva al debate entre personólogos y situacionistas. Análisis y Modificación de Conducta, 1978, Vol. 4, núm. 5. pp. 111-128.

(2) BLOCK, J. Advancing the psychology of personality: Paradigmatic shift or improving the quality of research. En D. Magnusson y N. S. Endler (Eds.): Personality at the crossoroads: Current issues in interactional psychology. Erlbaum, 1977, pp. 37-63.

(3) PERVIN, L. Current constroversies and issues in personality. John Wiley and Sons, 1978.

(4) Véase RUIZ FERNANDEZ, M. A. "Autocontrol: procesos cognitivos que influyen en la demora de la gratificación en niños», memoria de licenciatura no publicada, realizada bajo mi dirección.

(5) Op. Cit.. pág. 19. 